\title{
DIFFERENCES IN THE ACTION OF $\gamma$-AMINOBUTYRIC ACID ON BLOOD PRESSURE BETWEEN SOME ANIMAL SPECIES
}

\author{
HIDEHIKO TAKAHASHI, MASAKO TIBA, MASAO SUMI \\ AND HIROMICHI MATSUZAKI* \\ Department of Physiology, Tokyo Medical College, Tokyo, Japan
}

Our investigations about the effect of GABA on blood pressure had been performed using the rabbit, the dog and the cat as experimental animals $(1,2)$. In the course of these studies, we noticed that its effect varied quantitatively from species to species, although it showed likewise appreciable effect on blood pressure in various animal species.

In this paper, we have dealt with this variation of the effect of GABA on blood pressure between animal species in some details.

\section{METHODS}

Experiments were performed on rabbits, dogs and cats. Measurements of blood pressure and other experimental procedures were essentialy the same as described in the previous papers $(1,2)$.

RESULTS

As already reported (1), the effect of GABA on blood pressure in the rabbit was characteristic of remarkable lowering. However, a dual character of its effect-depressor and pressor-was revealed in unanaesthetized rabbits, when a large amount of GABA was injected intravenously.

In the dog, the action of GABA on blood pressure was essentially similar to that in the rabbit, although some differences were also observed. That is, its depressant effect was weaker in the dog than in the rabbit and its dual actions were observed even under anaesthetized condition.

Fig. 1 shows the effect of GABA on blood pressure of a dog under urethane anaesthesia. When a large amount of GABA was injected, the depressant effect was increased and prolonged, but the pressant effect appeared at the same time, although the latter was weaker and transient.

In unanaesthetized dogs, too, a small amount of GABA $(4 \mathrm{mg} / \mathrm{kg}$.) caused a fall of blood pressure, but its effect was rather weaker than under urethane anaesthesia. On the other hand, a large amount of GABA (about $23 \mathrm{mg} / \mathrm{kg}$.) produced only a sustained rise in blood pressure level.

Received for publication July 4, 1959.

*高橋日出彦, 千葉正子, 角雅夫, 松褕弘道 


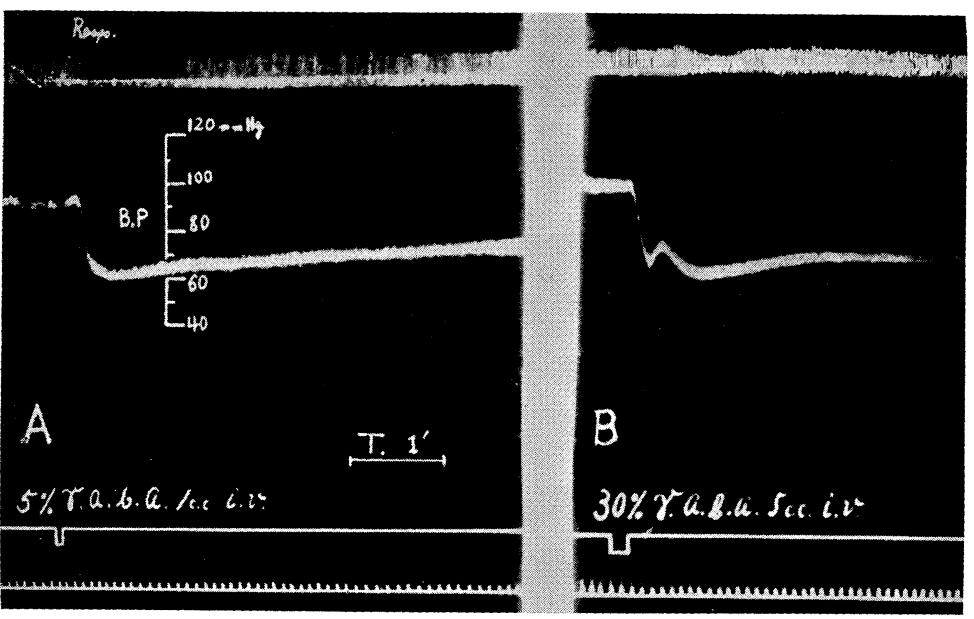

FIG. 1. Effect of GABA on blood pressure in a dog $(14 \mathrm{~kg}$.) under urethane anaesthesia.

$(A): 1 \mathrm{ml}$. of $5 \% \mathrm{GABA}$ solution was injected intravenously.

$(B): 5 \mathrm{ml}$. of $30 \% \mathrm{GABA}$ solution were injected.

In the cat, the effect of GABA on blood pressure was much weaker and varied from preparations to preparations. Fig. 2 shows typical two patterns of the effect of GABA observed in cats under urethane anaesthesia. A small amount of GABA could produce fall of blood pressure. But, its depressant action was in many preparations observed only transiently, and followed by a sustained rise in the level of blood pressure.

Fig. 3 shows the effect of a large amount of GABA on blood pressure in a cat. When a large amount was administered, three phases in the effect of GABA were observed, that is, the initial transient rising, the second lowering and the last sustained rising ones. Among these three phases, the second lowering phase was generally weak and transient, although it was sometimes considerably evident.

In rabbits, dogs and cats, respiration was at first inhibited and soon hyperventilation started following the application of GABA. Fall of blood pressure was accompanied with bradycardia.

Changes in peripheral circulation during the fall of blood pressure induced by GABA were investigated especially in rabbits and dogs and reported in the previous paper (2). In cat, paw volume was changed passively by changes in blood pressured during first and second phases, but in the third sustained rising phase it was diminished, suggesting that blood veins in the skin were contracted actively. The volume of the kidney was changed passively during all the phases and in the third phase it was augmented strikingly.

In unanaesthetized cats, GABA did not show any depressant effect on blood pressure and produced sustained rise alone by a large amount.

In intact cats, the lasting rise was most prominent among the effect of GABA on blood pressure, but after decerebration, any rise did not appear and depressant effect became considerably apparent (fig. 4). 


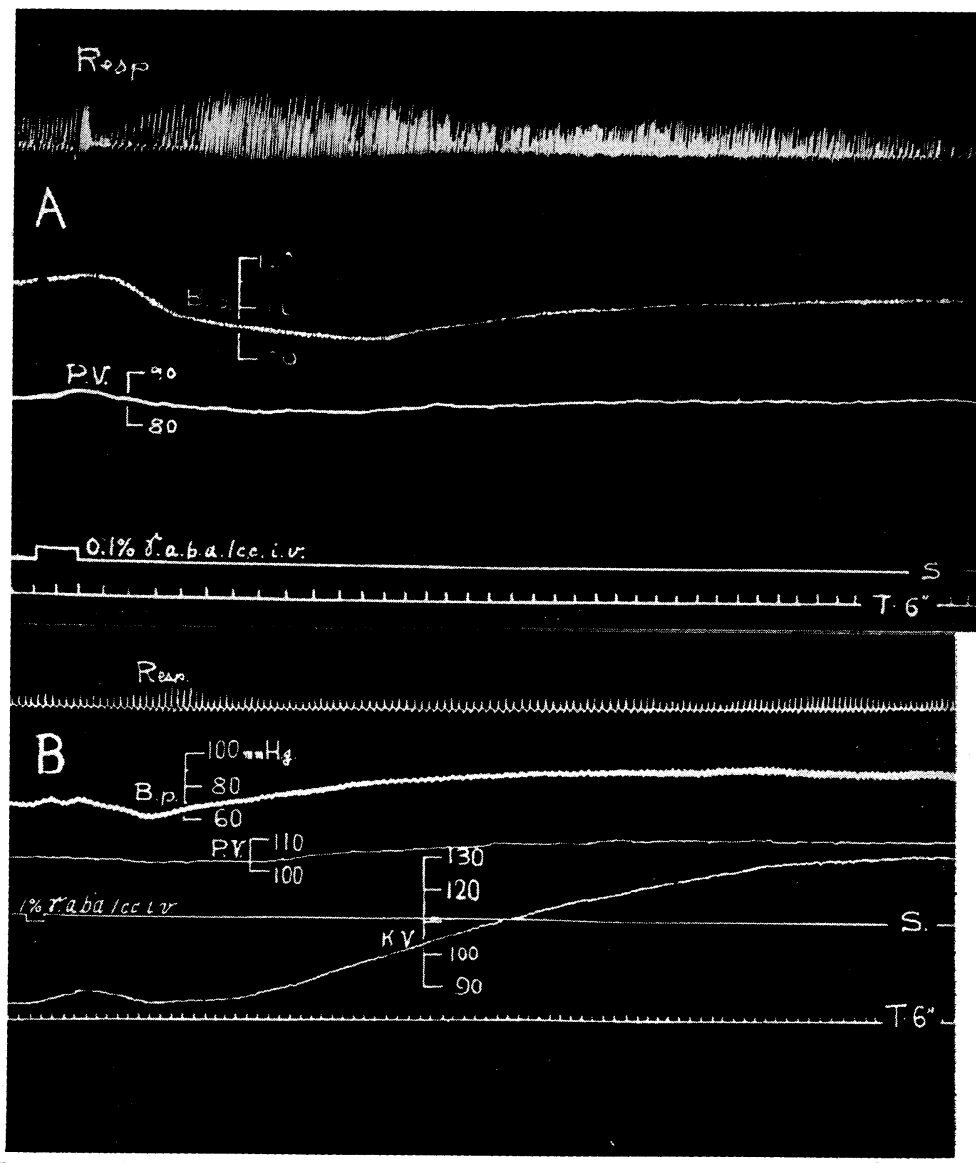

FIG. 2. Effect of a small amount of GABA on blood pressure in two cats under urethane anaesthesia. GABA was injected intravenously respectively $0.4 \mathrm{mg} / \mathrm{kg}$. in $\mathrm{A}$ and $5 \mathrm{mg} / \mathrm{kg}$. in $\mathrm{B}$.

B.P.: blood pressure, P.V.: the volume of the paw, K.V.: the volume of the kidney, Resp. : respiration.

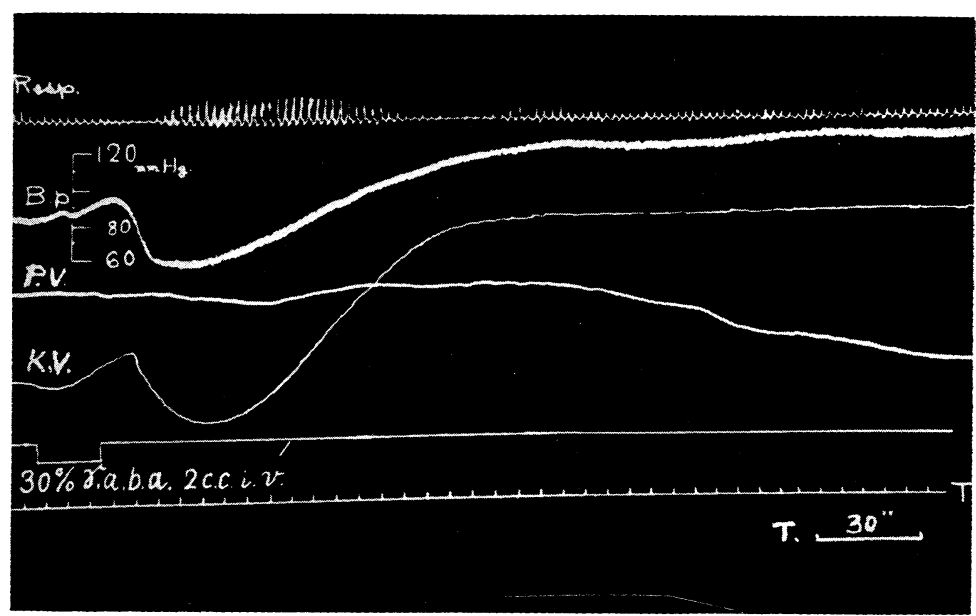

FIG. 3. Effect of a large amount of GABA on blood pressure in a cat under urethane anaesthesia. $2 \mathrm{ml}$. of $30 \% \mathrm{GABA}$ were injected intravenously. 


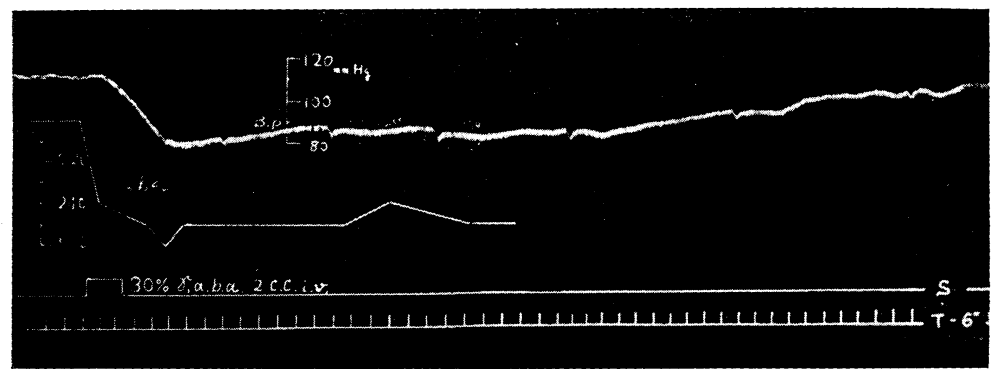

FIG. 4. Effect of a large amount of GABA on blood pressure in a decerebrate cat.

$2 \mathrm{ml} .30 \% \mathrm{GABA}$ were injected intravenously.

H.R. : heart rate/min.

\section{DISCUSSION AND SUMMARY}

The effect of the systemic application of GABA on blood pressure was more or less dual in the rabbit, the dog and the cat. Its depressant action was the strongest in the rabbit and the weakest in the cat. On the contrary, its pressant effect was observed most obviously in the cat and most obscurely in the rabbit. In the dog, both effects were likewise middle between these two species, although the depressant effect was observed more easily.

Although the mechanism of the pressant effect of GABA was not so completely investigated, the rise of blood pressure by GABA appeared to be due to its action on the higher central nervous system, because it was reduced with anaesthesia or completely disappeared after decerebration.

\section{REFERENCES}

1. Takahashi, H. ET AL. Jap. J. Physiol. 5: 334, 1955.

2. TAkAhashi, H. ET AL. Jap. J. Physiol. 8: 378, 1958. 